\title{
ESTUDO DE CASO DO HOSPITAL VETERINÁRIO DO CAMPUS II DA UNOESTE - PRESIDENTE PRUDENTE
}

Juliana Domingues Scatolon', Korina Aparecida Teixeira Ferreira da Costa².

${ }^{1}$ Discente do curso de Arquitetura e Urbanismo da Universidade do Oeste Paulista- UNOESTE. ${ }^{2}$ Docente do curso de Arquitetura e Urbanismo da Universidade do Oeste Paulista - UNOESTE

\section{RESUMO}

O artigo intitulado "Estudo de caso do hospital veterinário do campus II da Unoeste - Presidente Prudente", foi desenvolvido como parte do levantamento pertencente ao trabalho de conclusão de curso denominado "Reforma e readequação do hospital veterinário do campus II da Unoeste". Apresentam as análises do ambiente construído seguindo as questões de iluminação e ventilação natural, disposição das áreas de atendimento aos animais e fluxo de materiais utilizados em cirurgias, acesso dos profissionais que atuam no hospital e a mobilidade dos animais atendidos. Foram estudados os tipos de aberturas e materiais utilizados na construção, implantação da edificação e a influência do entorno no conforto térmico da edificação.

Palavras-chave: Hospital Veterinário, Conforto do ambiente, Incidência Solar, Salubridade, funcionalidade.

\section{INTRODUÇÃO E OBJETIVO}

O artigo busca relatar os resultados da análise referente do estudo de caso feito no Hospital Veterinário do Campus II da Unoeste, tendo como objetivo levantar os pontos positivos e negativos de um ambiente onde ocorrem grandes fluxos de pessoas e animais durante todo o dia, como parte do estudo de sua realidade atual para na sequencia do TCC chegar-se a uma proposta de reforma e readequação fundamentada em suas reais necessidades, para suprir suas deficiências e explorar suas potencialidades.

Neste estudo foram levantadas questões como incidência solar nas fachadas, as aberturas existentes no hospital, ventilação e iluminação natural dos ambientes, localização dos ambientes de acordo com as necessidades de atendimento, fluxo de pessoas, de materiais esterilizados e infectados. Estes pontos devem funcionar de forma adequada para que o atendimento dos animais e as condições dos trabalhadores sejam de boa qualidade.

O hospital veterinário da Unoeste foi construído a partir da necessidade de um local adequado para que os estudantes do curso de medicina veterinária fizessem residência, a construção do H.V. começou em meados do ano de 1989 tendo suas obras concluídas em 1990 e sendo inaugurado em 1991, em decorrência desta urgência na construção o hospital apresenta as deficiências apontadas neste estudo. 


\section{METODOLOGIA}

A investigação se fundamentará na abordagem qualitativa de pesquisa, utilizando-se da pesquisa de levantamento bibliográfico e da pesquisa documental, que segundo Teixeira (2000, p. 137), busca a correlação entre a teoria e os dados, entre o contexto e a ação, a partir da compreensão dos fenômenos por meio de sua descrição e interpretação. Para o trabalho com o estudo do tipo de levantamento bibliográfico ocorrerá inicialmente um levantamento das principais produções no contexto nacional de estudos, considerando a peculiaridade do objeto de estudo.

Para Taylor e Bogdan (apud SANTOS FILHO, 2007, p. 43):

[..] a pesquisa qualitativa rejeita a possibilidade de descoberta de leis sociais e está mais preocupada com a compreensão (verstehen) ou interpretação do fenômeno social, com base nas perspectivas dos atores por meio da participação em suas vidas. Seu propósito fundamental é a compreensão, explanação e especificação do fenômeno. O pesquisador precisa tentar compreender o significado que os outros dão à suas próprias situações.

Desse modo, percebe-se que a pesquisa qualitativa vale-se do método indutivo, segundo o qual parte da observação, da análise dos fatos particulares, dos registros para compor um quadro compreensivo para então constituir a generalização universal, ou seja, a teoria. O processo de indução vale-se do princípio do empirismo, no qual o conhecer é dar significado à realidade (KÖCHE, 1997, p. 62).

A metodologia utilizada na realização deste estudo teve como base os princípios elencados por Eduardo Grala da Cunha (2006), em sua publicação Elementos de Climatização Natural. O autor aborda três princípios para concepção de uma arquitetura bioclimáticos sendo eles, o lugar, a história e a cultura. O lugar oferece os valores climáticos, auxiliando na definição das formas construtivas e na escolha dos materiais de construção. Por outro lado a história mostra a adaptação do homem ao entorno e a sua evolução social, sendo rica no repertório arquitetônico compatível com a cidade. A cultura oferece os recursos e mecanismos do fazer humano para que se constitua um espaço habitável, analisando e ponderando os fatores possíveis da arquitetura.

Tendo como embasamento as exposições feitas por Cunha (2006) foram realizados estudos de insolação nas fachadas da edificação do H.V, estudos de fluxos de animais, pessoas e materiais do centro cirúrgico para a área esterilização, tipos de aberturas da edificação. Estes estudos foram utilizados para elaboração de um projeto de reforma e readequação como TCC do curso de arquitetura e urbanismo. 


\section{O HOSPITAL VETERINÁRIO DA UNOESTE}

O campus da universidade onde está inserido o hospital veterinário localiza-se as margens da rodovia Raposo Tavares no quilometro 572. O campus tem duas entradas que levam ao hospital veterinário, sendo uma principal e outra secundária pela rua dos fundos da universidade.

A área onde está implantado do H.V. é densa em vegetação de grande e médio porte, formando uma barreira natural para incidência de raios solares e dos ventos predominantes, sendo assim elas auxiliam na evaporação melhorando a umidade do ar e diminuindo as altas temperaturas.

As curvas de nível do terreno do campus são a cada cinco metros, como mostra a figua acima, o H.V está implantado na curva de nível 20,00 metros, para isto foi feito um recorte de 3,00 metros como mostra a figura abaixo.

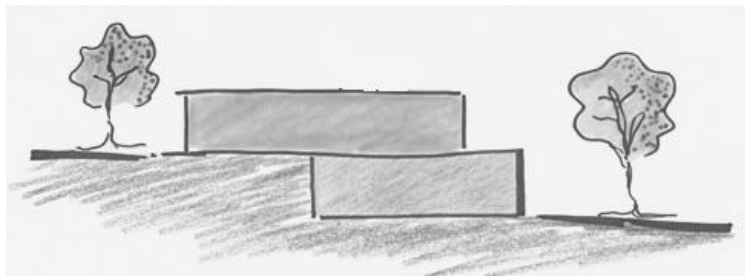

Figura 01. Croqui esquemático da Implantação da edificação

Fonte: Scatolon (2013)

A edificação é de alvenaria, com esquadrias basculantes metálicas e fechamento em vidro. Os ambientes estão dispostos de forma que laboratórios, ambulatórios, e centro cirúrgico de grandes animais recebam incidência solar da manha. Na fachada onde predomina o sol da tarde encontram-se ambientes como, centro cirúrgico de pequenos animais, canis de recuperação e isolamento, farmácia, esterilização e lavanderia. O prédio conta ainda com um pátio interno para iluminação e ventilação.

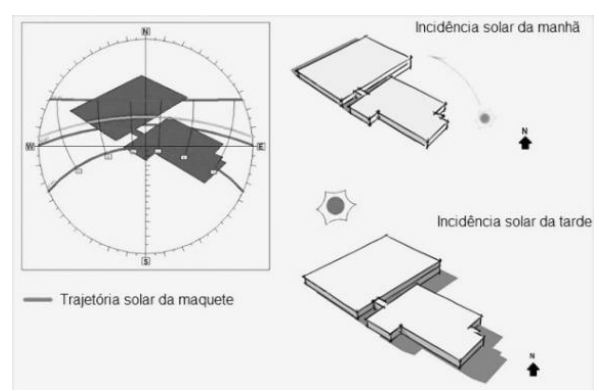

Figura 02. Implantação da edificação na carta solar 22ㅇ Sul e projeção da sombra na trajetória solar $^{3}$

\footnotetext{
${ }^{3}$ Dia escolhido para trajetória solar: 12/09/2012 ás 08:00h da manha e ás 16:00h da tarde 
Fonte: Adaptado de Scatolon (2013, p. 74 e 75)

Cunha (2006, p. 36) expõe que [...] "não existe uma arquitetura bioclimática, mas a arquitetura, simplesmente". Compreendemos então que a arquitetura adequa-se ao conjunto de valores climáticos que o local oferece para tornar-se bioclimática, ou seja leva em consideração as características térmicas do local, a luminosidade e a direção dos ventos. Estes fatores climáticos influenciam no comportamento dos materiais utilizados na edificação levando em consideração a absorção e radiação de calor, assim como nas formas de aberturas para passagem da ventilação.

Segundo Frota e Schiffer (2003) a topografia do local tem grande influencia na temperatura do ar, locais mais acidentados como baixadas possuem temperatura mais elevada que locais altos pois locais acidentados formam barreiras aos ventos, dificultando a renovação do ar.

Partindo deste pensamento a análise do hospital veterinário tem como relevância alguns pontos, como a técnica construtiva, a implantação da edificação no campus, o entorno da edificação e a disposição dos ambientes.

O prédio é constituído de alvenaria, janelas basculantes com fechamento em vidro, revestimento de piso de granilite, em alguns ambientes por questão de salubridade o revestimento é o porcelanato branco e nas outras paredes tinta acrílica.

Apresenta-se abaixo a tabela a referente ao comportamento da edificação em relação a iluminação natural dos ambientes que compõem o hospital veterinário. 
Tabela 1. Avaliação da iluminação e ventilação natural nos ambientes estudados do HV da Unoeste

\begin{tabular}{|c|c|c|c|c|}
\hline \multirow{2}{*}{$\begin{array}{l}\text { AMBIENTES (Pavimento I) } \\
\text { Hall de entrada }\end{array}$} & \multicolumn{2}{|c|}{ ADEQUADO } & \multicolumn{2}{|c|}{ INADEQUADO } \\
\hline & 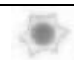 & $\approx$ & & \\
\hline Secretária & & & 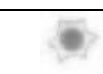 & $\approx$ \\
\hline Banheiros & & & 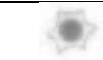 & $\approx$ \\
\hline Sala de aula & & & 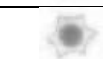 & $\approx$ \\
\hline Sala dos Professores & 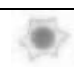 & $\approx$ & & \\
\hline Ambulatório I e II & & & & $\approx$ \\
\hline Ambulatório de Emergência & & & $\bullet$ & $\approx$ \\
\hline Fluídoterapia & & & 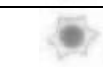 & $\approx$ \\
\hline Vestiário Feminino & & & 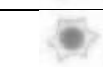 & $\approx$ \\
\hline Canil de Internação & $\bullet$ & & & $\approx$ \\
\hline Ante-câmara & $\bullet$ & $\approx$ & & \\
\hline Isolamento I e II & 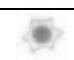 & $\approx$ & & \\
\hline Ante - sala & & & 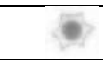 & $\approx$ \\
\hline Coordenação & & & $\bullet$ & $\approx$ \\
\hline
\end{tabular}

Fonte: Scatolon (2013)

Alguns dos ambientes considerados inadequados nas questões de iluminação e ventilação natural como a secretária, banheiros, vestiários, fluídoterapia estão dispostos na edificação de forma que suas aberturas sejam superiores e voltadas para corredores com pouca iluminação e ventilação.

As salas destinadas aos ambulatórios e sala de aula, possuem divisórias improvisadas para separação dos ambientes, estas funcionam como um bloqueio da iluminação natural e da ventilação, acarretando na utilização da iluminação artificial ao longo do dia. Os canis localizados no primeiro pavimento tem a iluminação barrada pela densa vegetação na fachada onde foram implantados.

A sala da coordenação e antessala estão localizadas na fachada norte da edificação, que possui densa vegetação o que dificulta a passagem dos raios solares.

A tabela 2 apresenta a análise de iluminação e ventilação natural dos ambientes que compõem o segundo pavimento do hospital veterinário, levando em consideração ainda os princípios elencados para a análise do primeiro pavimento. 
Tabela 2. Avaliação da iluminação e ventilação natural nos ambientes estudados do HV da Unoeste

\begin{tabular}{|c|c|c|c|c|}
\hline \multirow{2}{*}{$\begin{array}{l}\text { AMBIENTES (Pavimento II) } \\
\text { Secretária }\end{array}$} & \multicolumn{2}{|c|}{ ADEQUADO } & \multicolumn{2}{|c|}{ INADEQUADO } \\
\hline & & & $\bullet$ & $\approx$ \\
\hline Laboratório de análise clinica & & & 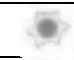 & $\approx$ \\
\hline Laboratório de Parasitologia & & & $\bullet$ & $\approx$ \\
\hline Laboratório de Microbiologia & & & 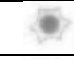 & $\approx$ \\
\hline Sala dos Professores/ residentes & 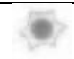 & $\approx$ & $\bullet$ & $\approx$ \\
\hline Centro Cirurgico Grandes Animais & & & $\bullet$ & $\approx$ \\
\hline Paramentação & 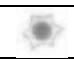 & $\approx$ & & \\
\hline Sala de Indução & $\bullet$ & $\approx$ & & \\
\hline Área de raio $-x$ & 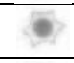 & $\approx$ & & \\
\hline Depósito & 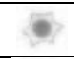 & $\approx$ & & \\
\hline Produto Químico (depósito) & 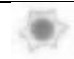 & $\approx$ & & \\
\hline Copa & & & $\bullet$ & $\approx$ \\
\hline Lavanderia & & & 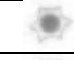 & $\approx$ \\
\hline Esterilização & & & 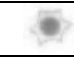 & $\approx$ \\
\hline Distribuição & $\bullet$ & $\approx$ & & \\
\hline Manipulação & & & 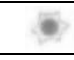 & $\approx$ \\
\hline Farmácia & 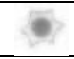 & $\approx$ & & \\
\hline Estoque (farmácia) & & & $\bullet$ & $\approx$ \\
\hline Laboratório de Reprodução & & & 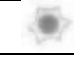 & $\approx$ \\
\hline Canil de recuperação & 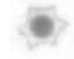 & $\approx$ & & \\
\hline Centro Cirúrgico de Pequenos animais & 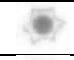 & $\approx$ & & \\
\hline Pós Operatório & 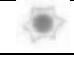 & $\approx$ & & \\
\hline DML & & & $\bullet$ & $\approx$ \\
\hline Hidratação e Parto/ultrassonografia & & & $\theta$ & $\approx$ \\
\hline Arquivo & & & 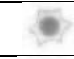 & $\approx$ \\
\hline Vestiários & & & $\theta$ & $\approx$ \\
\hline
\end{tabular}

Legenda: $\quad$ Iluminação Natural $\approx$ Ventilação Natural

Fonte: Scatolon (2013)

Os ambientes do segundo pavimento que apresentam resultados negativos em relação a iluminação e ventilação como a secretária, laboratório de análise clínica, parasitologia, microbiologia possuem divisórias para criar ambientes que bloqueiam a iluminação e a ventilação.

O centro cirúrgico de grandes animais teve as janelas pintadas de tinta óleo impedindo a iluminação natural e a ventilação do ambiente. A copa fica localizada ao lado do depósito de produtos químicos e possui apenas uma porta para iluminação e ventilação e não possui janelas. 
A lavanderia e a esterilização tornam-se escuras por causa da densa vegetação que bloqueia a passagem da iluminação e ventilação, a sala destinada a estoque da farmácia assim como o centro cirúrgico de grandes animais, teve as janelas pintadas por tinta óleo, bloqueando a passagem dos raios solares.

A sala de hidratação e parto, arquivo e DML são ambientes que não possuem janelas, por estarem voltados para o corredor do centro cirúrgico de pequenos animais, os vestiários localizados no segundo pavimento possuem as suas aberturas na parte superior da parede voltado para o corredor interno, outro fator que impede a iluminação nos vestiários é a utilização de vidro fosco no fechamento das esquadrias.A imagem abaixo exemplifica alguns dos problemas apresentados acima.

As instituições destinadas a área da saúde apresentam cuidados em relação a salubridade e proliferação das bactérias, por tanto é importante que materiais infectados e esterilizados não se encontrem no mesmo corredor, sendo assim esse é um dos problemas apresentado pelo hospital. A figura 04 apresenta o fluxo destes materiais do centro cirúrgico até área de esterilização e lavanderia.

Os fluxos apresentados acima que vão da sala de cirurgia para as áreas de esterilização não devem se cruzar para evitar a contaminação de materiais limpos por materiais infectados, acarretando na proliferação de bactérias e doenças. Pode-se observar na figura acima que todos os materiais passam pelo mesmo corredor.

O hospital apresenta ainda problemas com acesso aos pavimentos, pois edificações destinadas a este tipo de atendimento seja á humanos ou animais devem favorecer a acessibilidade e locomoção dentro da edificação, sendo assim o h.v da Unoeste apresenta apenas uma escada interna do primeiro pavimento para o segundo, dificultando assim a locomoção dos animais e a circulação dos trabalhadores muitas vezes dificultando o atendimento aos pacientes.

\section{CONCLUSÃO}

Os estudos feitos no hospital veterinário levantaram problemas de iluminação e ventilação na maioria dos ambientes, devido a intervenção humana após a execução do projeto arquitetônico como a adaptação de ambientes para o desenvolvimento das atividades, por meio da implantação de divisórias em frente ás janelas ou a pintura dos fechamentos das esquadrias procurando amenizar a incidência solar de forma inadequada. Foi observada na maioria dos 
ambientes a utilização ao longo do dia da iluminação artificial, acarretando no alto consumo de energia.

A existência do pátio interno pouco auxilia na ventilação e iluminação, pois as aberturas não são suficientes, assim como o tipo de esquadrias que fazem o fechamento da área, não auxiliam na passagem de ar e raios solares, por serem basculantes, contudo um bom aproveitamento do mesmo poderia promover a melhoria na qualidade de vida do hospital.

Foram encontrados problemas de acessibilidade, o hospital veterinário não apresenta rampas de acesso a cadeirantes possuindo apenas uma escada interna de acesso que também dificulta a locomoção de animais e trabalhadores. A disposição de alguns ambientes dificulta o bom atendimento aos animais, pois centro cirúrgico deveria estar próximo da farmácia e dos laboratórios para que em caso de emergência o atendimento seja rápido não prejudicando a saúde dos animais.

A pesar de todos os problemas encontrados no hospital veterinário e de ser um ambiente sobrecarregado pelas situações tensas do dia a dia e pela falta de infra estrutura adequada para o atendimento dos animais e até mesmo para o bom desenvolvimento do trabalho, foi observado a dedicação, o respeito e amor a função que cada funcionário desempenha para garantir o bom atendimento e amenizar o sofrimento dos animais que necessitam de atendimento.

\section{REFERENCIAS}

CUNHA, Eduardo Grala (org.). Elemento de arquitetura de climatização natural: método projetual buscando eficiência nas edificações - Porto Alegre: Masquatro Editora, 2006. 188p.

FROTA, Anésia Barros. SCHIFFER, Sueli Ramos. Manual do Conforto térmico: arquitetura/ urbanismo - São Paulo: Studio Nobel, 2003. 241p.

SCATOLON, Juliana Domingues. Reforma e readequação do hospital veterinário do Campus II da Unoeste - Presidente Prudente - SP, 2013. 113p.

TEIXEIRA, E. As três metodologias. 2aa.ed. São Paulo: Vozes, 2000.

KÖCHE, J. C. Fundamentos de metodologia científica: teoria da ciência e iniciação à pesquisa. 22. ed. São Paulo: Vozes, 2004. 